\title{
EL GÉNERO AUTOBIOGRÁFICO Y LA CONSTRUCCIÓN DEL SUJETO AUTORREFERENCIAL
}

\author{
Francisco Rodríguez
}

\begin{abstract}
RESUMEN
En este artículo se estudia, desde un punto de vista diacrónico, el género autobiográfico y la construcción que éste plantea de un sujeto autorreferencial. Se analizan cuatro perspectivas en relación con dicho género: la de Whilhelm Dilthey, quien entendía el género como un método de entendimiento de los principios organizativos de la experiencia. Por su parte, Georges Gusdorf polemiza contra el supuesto positivista de que es posible reconstruir el pasado objetivamente, e indica que la autobiografía es más bien la construcción de los recuerdos, un yo que ha vivido elabora un segundo yo, creado en la experiencia de la escritura. En tercer lugar, se considera la posición de Paul de Man, quien comprendía la autobiografía como desfiguración, encadenamiento tropológico que evidenciaba la retórica de su construcción. Seguidamente, se estudia la perspectiva de Bajtín, quien asume la autobiografía como la construcción de un héroe autorreferencial. Se concluye indicando nuestra propia valoración del género.
\end{abstract}

\begin{abstract}
This is a diachronic study of the autobiographic genre and the construction of a self-referential subject it put forths. Four viewpoints are analyzed: Whilhelm Dilthey's, who considers genre a method to understand the organizational principles of experience. Goerges Gusdorf debates against the positivist premise holding that it is possible to objectively reconstruct the past. Besides, he holds that autobiography is rather the construction of memories: a self that has lived elaborates a second self, buildt in the experience of writing. Thirdly, Paul de Man's perspective is included. He understood autobiography as defiguration, tropological linking portraying the rhetoric of its own construction. Finally, Bajtin's viewpoint is included. $\mathrm{He}$ takes biography as the construction of a self-referential hero. To conclude, the author's own assessment of this genre is discussed.
\end{abstract}

\section{Introducción}

Dice Manfred Schmeling (1984) que la crítica literaria comparada se debe ocupar de la historicidad del fenómeno textual enfatizando en la confrontación de diversas actitudes críticas, centrando la discusión en los problemas metodológicos.

Siguiendo esa idea, el objetivo de este artículo es analizar desde un punto de vista diacrónico el género autobiográfico y la construcción que este plantea de un sujeto autorreferencial.

La historicidad, en vez de la variabilidad, es la categoría metodológica que justifica una investigación diacrónica, en este caso de la construcción teórica del concepto de género autobiográfico. 
Nuestro análisis, en un primer momento, pretende cuestionar cuatro puntos de vista en relación con dicho género, los cuales han ayudado a estructurar históricamente la evolución de la autobiografía; con ello se intentan señalar las implicaciones de carácter epistemológico y metodológico que sustentan tales concepciones. Asimismo, nuestra exposición es cronológica, con el fin de acceder en orden de surgimiento a las discusiones que han venido transformando la concepción del objeto de estudio.

En un segundo momento, a partir de la perspectiva epistemológica de Bajtín, procuramos reconceptualizar la noción de autobiografía para ofrecer nuestro propio criterio sobre dicho género.

En primer lugar nos ocupamos de Wilhelm Dilthey, quien a fines del siglo pasado teorizó acerca de la importancia de la autobiografía para la comprensión histórica, en tanto método de entendimiento de los principios organizativos de la experiencia. La autobiografía corresponde a la reconstrucción de la vida, como medio de interpretación de la realidad histórica en que vive el autor de la autobiografía.

Luego, en su artículo de 1956, "Condiciones y límites de la autobiografía", Georges Gusdorf polemiza contra el supuesto positivista de que es posible reconstruir el pasado objetivamente, e indica que la autobiografía es más bien la construcción de los recuerdos, un yo que ha vivido elabora un segundo yo, creado en la experiencia de la escritura; así el énfasis de la autobiografía debe ser el "crear" y, al crear, "ser creado". El interés de la teoría ya no se centrará en las relaciones entre texto e historia, sino entre texto y sujeto. Aquí se intenta discutir cómo un texto representa a un sujeto. Desde esta visión, la autobiografía ha perdido su condición de objetividad y el autor su papel de autoridad al pasar de testigo objetivo a ente en busca de una identidad.

Después de una breve exposición de los planteamientos de Philippe Lejeune, acerca de la autobiografía como pacto contractual, nos centramos en los problemas del sujeto y del lenguaje, es decir, en la autobiografía como escritura. El texto que se discute es "La autobiografía como desfiguración" de Paul de Man, en donde el autor intenta penetrar en la autobiografía misma, en su constitución retórica para tratar de comprender cómo ese tipo de textos engendra los espejismos del yo y del poder cognoscitivo de la autobiografía. Para De Man, este género no proporciona conocimientos sobre un sujeto que cuenta su vida, sino que se distingue por su estructura peculiar en que dos sujetos se reflejan mutuamente y se constituyen a través de esa reflexión. La autobiografía deviene en forma de textualidad que posee la estructura del conocimiento y de la lectura. Esto nos conduce a los elementos que históricamente se han debatido como definidores del género, y a proponer, desde la teoría bajtiniana, nuestra perspectiva de comprensión del mismo, que intenta asumir el espacio autobiográfico como una zona de enunciación de la autoconciencia, donde confluyen, a partir de un sujeto de enunciación, elementos referenciales (construcciones de), antropológicos, históricos, mediatizados por construcciones tropológicas que le asignan verosimilitud a los textos.

\section{Génesis de la autobiografía}

De acuerdo con James Olney (1991), la historia de la autobiografía se puede dividir en tres grandes etapas, atendiendo a la relación sujeto-objeto, propia, en este caso, de la correspondencia entre un sujeto de escritura que se construye a sí mismo, la historia, el héroe u 
objeto, y el lugar de las mediaciones, el lenguaje. La primera de ellas da cuenta del "Bios", en donde se manifiesta la relación texto-historia; la segunda, etapa del "Autos" interpreta la relación texto-sujeto; y la última, la etapa del "Grafé" alude a las relaciones texto-sujeto-lenguaje.

A partir del concepto de identidad como referencialidad, el crítico alemán Bernd Neumann define la autobiografía mediante la distinción entre ella y la memoria. A la vez que plantea un límite preciso entre ambos géneros, a los que considera hijos de la "biografía" en general:

Si las memorias describen los acontecimientos de un individuo como portador de un rol social, la biografía narra la vida de un hombre no socializado, la historia de su devenir y de su formación, de su crecimiento en la sociedad. Las memorias comienzan prácticamente tan solo con el logro de la identidad, con la aceptación del rol social, y la autobiografía termina allí (1973: 33-4).

Así pues, las memorias apuntan al relato de la vida social, de la participación de un hombre en cargos públicos.

Por su parte, la autobiografía corresponde al relato de acontecimientos privados: "Terminando las memorias ante el ámbito privado, terminan justamente allí donde comienza la autobiografía" (1973: 20).

Para este autor, la tipología genérica -distinción autobiografía/memoria- está planteada por la incorporación del individuo a los procesos económico-productivos del sistema capitalista. Es autobiografía cuando el texto relata el período de la infancia, la adolescencia o la vejez, en el sentido de que son acontecimientos privados, propios del sujeto, de su vida íntima. Por su parte, las memorias son el relato del período productivo de la persona, es decir, cuando desempeña un cargo reconocido socialmente. Desde este punto de vista, el ámbito de lo privado no tiene ninguna repercusión en la vida social de un pueblo. El género se delimita y modeliza por el contenido temático, no por alguna categoría de poética histórica ni de forma artística; el texto no se analiza como escritura, sino como la construcción de un sujeto referencial que corresponde con el sujeto de enunciación. Los problemas del significante y de la constitución del yo están fuera de su comprensión.

De acuerdo con Neumann, la autobiografía constituye un género puramente europeo, cuyo inicio lo representa San Agustín con sus Confesiones. No obstante, en tanto género se establece en el Renacimiento, específicamente en las ciudades italianas.

En el campo de estas poderosas repúblicas-ciudades regidas democráticamente en parte y en parte aristocráticamente pero siempre gobernadas por el comercio, crecieron las primeras grandes autobiografías...

La forma económica del capitalismo, que en sus primeras versiones consistía en la liberación de un provecho casi desaforado, creó la base para la conciencia que surge de nuevo en el Renacimiento, y para una individualidad única y limitada (1973: 134-5).

Para el autor, el inicio de la autobiografía está emparentado con el origen del desarrollo de la mentalidad burguesa, puesto que en ella se manifiesta el valor que la burguesía tiene del individuo en tanto motor de la actividad económica y cultural. Esto significa que el relato de la propia vida no tiene cabida más que en la mentalidad individualista propiciada por la burguesía, a partir del desarrollo de las ciudades después del siglo XIV. La autobiografía expone, en sus inicios, el individualismo como una nueva forma de vida.

Karl J. Weintraub (1991) coincide con Neumann en que el nacimiento de la autobiografía tiene que ver con el surgimiento de la conciencia individual, emparentada con el desarrollo de la vida burguesa. 
Afirma que en las sociedades clásicas no existía esta conciencia individual, ya que la concepción de la personalidad se emparentaba con una prolongación de las omnipresentes realidades sociales; específicamente, la evolución de la personalidad estuvo dominada por el ideal social y religioso del guerrero perfecto, el héroe colectivo, la imagen del hombre público dominaba la formación de las generaciones. En este sentido, afirma, "es muy significativo que una personalidad homérica como la de Telémaco ante la pregunta ¿quién eres tú? responda: yo soy Telémaco, el hijo de Odiseo, el hijo de Laertes, el hijo de Autolicus" (1991: 26). Recordemos que para el surgimiento del Imperio Romano se manifiesta un cambio en la conciencia del intelectual acerca de la realidad y de la historia que consiste en mirarse en sus orígenes, es decir se plantea una visión temporal-lineal del acontecer. Por su parte, la visión griega del ser está mediatizada por la idea de polis, comunidad — guerra— dada la sujeción a la naturaleza, a los dioses y a los mitos; no hay, pues, noción de individualidad.

Con el advenimiento del cristianismo se acentúa el giro hacia la personalidad interior. El ideal de la personalidad es relacionarse y parecerse al símbolo teológico. El modelo se convierte en el monje, el asceta que relega su vida al creador. La visión de la historia fue la providencial que sostenía como propósito básico la salvación del hombre por medio del cumplimiento del plan de Dios:

Así, el ideal de un artifex vitae independiente, que busca configurar su propia vida en orgullosa batalla con el destino, deja paso al fiel sirviente del Señor para quien la principal virtud es la humildad (1991: 26).

Esto, unido a las invasiones y la consecuente hegemonía imperial romana, crea ese giro. Si bien el cristianismo teologal introduce la visión teleológica de la historia, la historiografía política de Polibio y sucesores y la enseñanza oficial de la historia venían induciendo el cambio en la conciencia que se mira en los orígenes familiares, en la fundación de las ciudades (pater familias) y de la nación romana imperial. En ese marco resurge la biografía de reyes, príncipes, emperadores y casas reales. Es el caso de la visión cristiana de la historia. En San Agustín, el introductor de la autobiografía, la conciencia individual se niega a mirarse en una relación de pertenencia a la ciudad histórica.

La autobiografía es un texto que no se desarrolla en la antigüedad, precisamente porque la idea de comunidad -en general- es más fuerte que la de individuo, concepto que está ligado a lo sumo a la idea de héroe guerrero.

Luego, como indicamos arriba, a partir del Renacimiento el hombre occidental ha desarrollado un apego por el ideal de la personalidad en tanto individuo que realiza su propia vida apegado a valores de uso y de cambio. Unido a este desarrollo de la individualidad está la evolución del género autobiográfico, en cuanto forma cultural que da expresión a la historia personal. Sin embargo, para Weintraub, la consolidación de la individualidad debe esperar hasta el advenimiento del historicismo: "Una visión total de la individualidad solo surgió en su forma definitiva a finales del siglo dieciocho y dependía de un sentido histórico más extensamente desarrollado" (1991: 30).

Debemos recordar que hablamos de la constitución de la autobiografía como género, ya que, como plantearemos más adelante, sí existieron formas autobiográficas en la antigüedad grecolatina y en la Edad Media. Concretamente, este último período fue rico en hagiografías y biografías, en tanto tópicos ligados al problema de la monarquía, su legitimación en el pasado, 
en la sangre, la descendencia y la disputa con la iglesia por la formación de los principados dentro de los feudos. Esto se mira con claridad ante la formación del imperio Carolingio en el siglo IX y X. Aunque, estamos claros, el tema no es el de la individualidad, sino más bien el de la biografía, en tanto recuento de la vida pública ligada a la monarquía.

\section{La autobiografía, método y mímesis}

Las primeras reflexiones teóricas en torno al problema de la autobiografía corresponden al filósofo alemán Wilhelm Dilthey. A este autor le interesó dicho género en tanto instrumento para la comprensión histórica, ya que lo consideró como un método de entendimiento de los principios organizativos de la experiencia. La autobiografía corresponde a la reconstrucción de la vida, por medio de la interpretación de la realidad histórica en que vive el autor de los textos autobiográficos. En El mundo histórico señala:

La autobiografía es la forma suprema y más instructiva en que se nos da la comprensión de la vida. En ella el curso de una vida es lo exterior, la manifestación sensible a partir de la cual la comprensión trata de penetrar en aquello que ha provocado este curso de vida dentro de un determinado medio. Y, ciertamente, quien comprende este curso de vida es idéntico con aquel que lo ha producido. De aquí resulta una intimidad especial del comprender (1944: 224).

Para este pensador, el trabajo autobiográfico es el resultado de un proceso de desarrollo vital; la escritura se realiza en un período de madurez, puesto que al escribir el sujeto intenta comprenderse a sí mismo (y a la vez a la historia de su período vital) buscando la conexión histórica de su vida, luego de haber atravesado vivencias que le han dado valor a su existencia, después de haber cumplido planes realiza una retrospección desde el presente. Ello implica seleccionar los momentos más significativos y olvidar el resto, además de que deja constancia de los errores, los cuales ya han sido rectificados gracias al transcurrir temporal.

Las tareas más inmediatas para la captación y exposición de la conexión histórica están ya realizadas, las unidades de esa evolución se han formado en las concepciones de vivencias, a la vez que dichos momentos vitales se han seleccionado en orden de importancia; por lo tanto, la vida misma ha hecho el trabajo de la exposición histórica.

Una vez seleccionadas las vivencias, en el desarrollo de ellas se ha manifestado una conexión que no es simple copia del curso real de la vida de un determinado número de años, se trata de un comprender que el individuo llega a saber de su conexión vital. En consecuencia, "en este punto nos acercamos a las raíces de toda captación histórica. La autobiografía no es más que la expresión literaria de la autognosis del hombre acerca del curso de su vida" (1944: 225).

Se evidencia en esta perspectiva la identificación del autor con el sujeto de la escritura y la credibilidad en la certeza de que es posible la reconstrucción verdadera de la vida pasada, más como autovaloración de carácter moralizante y pedagógico.

Dilthey inaugura, entonces, además de un método hermenéutico de comprensión histórica, una primera etapa dentro de la consideración del género autobiográfico, en tanto que analoga la relación sujeto de la escritura/ autor del texto; estamos en la concepción de autobiografía como reflejo, reconstrucción verídica, objetiva y comprobable de la vida que le proporciona el conocimiento de sí mismo al autobiógrafo, además de conocimiento confiable, sistemáticamente adquirido, a quienes lo leen. 
Esta posición de Dilthey no debe considerarse una línea de reflexión del pasado, puesto que incluso en nuestra época tiene sus seguidores. Si se ha asumido en esta exposición el criterio diacrónico para la presentación de las distintas teorías acerca del género autobiográfico, ello no introduce ningún tipo de valoración vertical, ya que toda reflexión responde a los códigos gnoseológicos de cada época. Pero esto tampoco implica que, conforme se van transformando las perspectivas teórico-metodológicas, las ideas del pasado no posean sus seguidores.

El proceso del conocimiento demuestra que en nuestra historia, las posiciones epistemológicas alternan y recuperan formas de ver los fenómenos nunca estables ni causales, sino dialógicas y fluctuantes; aunque a veces discordantes con las convenciones más aceptadas en una determinada comunidad epistemológica. Un ejemplo concreto referido a nuestro estudio es la visión que sigue Bernd Neumann (1970) para establecer su distinción entre memoria y autobiografía y para asignarle sus determinaciones al género, posición deudora de la perspectiva de Dilthey. Asimismo, Anna Caballé (en un artículo publicado en 1987) analoga la escritura autobiográfica con el referente histórico al que alude el texto. Así, el sujeto de enunciación se homologa con el escritor-ser humano que habita en determinado espacio geográficocultural. Indica la autora que en la literatura del yo "la necesidad de tener en cuenta a quienes han de recibir la obra obliga al autobiógrafo, en general, a seleccionar su material en una determinada dirección; a no enfrentarse demasiado, por ejemplo, con los sentimientos y las opiniones imperantes; a respetar en lo posible convicciones y tradiciones culturales; a reprimir, en fin, la libre reflexión sobre uno mismo y reducirla a cauces aceptables por temor a ser penetrado, descifrado, desposeído de todos sus secretos, juzgado" (1987: 105). Y más adelante agrega: "El escritor que decide hablar de sí sin subterfugios aparentes se ve condicionado por la inevitable proyección del personaje que es él mismo, y debido a esta dimensión pública, trascendente, de la obra autobiográfica, el autor difícilmente puede llegar a comunicarse tal cual es..." (1987: 106).

Esta orientación en la comprensión autobiográfica, para la consensualidad teórica, se extiende hasta aproximadamente los años 50, específicamente hasta 1956, fecha en que aparece el artículo de Georges Gusdorf "Condiciones y límites de la autobiografía", donde se supera la identificación sujeto de enunciación / autor del texto.

\section{La autobiografía, construcción de un sujeto}

Georges Gusdorf parte de la idea de que la autobiografía es un género firmemente establecido. Admite que la primera referencia a este tipo de escritura son las Confesiones de San Agustín; sin embargo, su verdadero origen está en el Renacimiento. Asimismo, estima el autor que es un fenómeno propio de la cultura occidental: "Por otra parte, no parece que la autobiografía se haya manifestado jamás fuera de nuestra atmósfera cultural; se diría que manifiesta una preocupación particular del hombre occidental" (1991: 9).

Este género tiene que ver con la preocupación del hombre occidental de complacerse consigo mismo, de considerarse privilegiado y digno de interés para los demás. En el origen del género se encierra un principio del placer narcisista: "El autor de una autobiografía da a su imagen un tipo de relieve en relación con su entorno, una existencia independiente; se contempla en su ser y le place ser contemplado, se constituye en testigo de sí mismo; y toma a los demás como testigos de lo que su presencia tiene de irremplazable" (1991: 10). 
Por otra parte, siguiendo un presupuesto antropológico, Gusdorf indica que el género fue posible cuando el ser humano salió del cuadro mítico e ingresó en la historia; en otras palabras, cuando su conciencia transita del mito al logos y logra un desarrollo de este, desde su expresión formal filosófica a la racionalidad historicista. Esto implica una revolución espiritual de la humanidad, transformación que tiene que ver con el surgimiento de la curiosidad de la persona para consigo misma, con el despertar de la autoconciencia.

El género autobiográfico supone que el artista y el modelo coinciden, el historiador se toma a sí mismo como objeto. El yo autobiográfico se considera digno de la memoria de los hombres, es decir, un personaje modelizante. Esta actitud es típica del hombre del Renacimiento. Tal como lo apuntábamos más arriba, solo en este período, cuando la cultura occidental estaba evolucionando del símbolo medieval al signo renacentista, es posible que el hombre se considere a sí mismo, en su propia materialidad, objeto digno de la memoria de los demás.

Por otra parte, para Gusdorf la autobiografía no consiste en el recuento verídico de la vida, sino en la construcción de un yo por una memoria que a veces falla, con lo cual los recuerdos se mediatizan:

La recapitulación de lo vivido pretende valer por lo vivido en sí, y, sin embargo, no revela más que una figura imaginada, lejana ya y sin duda incompleta, desnaturalizada además por el hecho de que el hombre que recuerda su pasado hace tiempo que ha dejado de ser el que era en ese pasado.(1991: 13).

La tarea de la autobiografía consiste en intentar elaborar un yo, que es el reemplazo construido por la memoria de aquel que en realidad vivió los hechos que se recuerdan. Sin embargo, la primera trampa en esa reconstrucción es la ilusión de racionalidad y lógica que le asigna la narración al texto. Se confunde la narratividad con la conciencia verídica, "en otras palabras, la reflexión inherente a la toma de conciencia es transferida, por una especie de ilusión óptica inevitable, al dominio del acontecimiento" (1991: 15). La ilusión empieza cuando la narración le da sentido al acontecimiento, el cual, en el momento de su aparición, posiblemente tenía muchos, o quizá ninguno.

La autobiografía deviene en una versión del pasado, en una reconstrucción revisada y corregida que se intenta verosimilizar como la "verdad real", por ello la autobiografía "no es la simple recapitulación del pasado; es la tarea, y el drama, de un ser que, en un cierto momento de su historia, se esfuerza en parecerse a su parecido. La reflexión sobre la existencia pasada constituye una nueva apuesta" (1991: 15).

Gusdorf privilegia el valor antropológico de la autobiografía antes que sus características literarias, ya que en dicho género opera una especie de autocreación que se lleva a cabo desde el presente. El sujeto autobiográfico se construye como mejor se recuerda, es el esfuerzo de un escritor por darle sentido a su pasado; por ello Gusdorf sostiene la necesidad de reinvertir la consideración del género en tanto portador de certezas, y apreciarlo como la elaboración del "autos", del yo realizado por la memoria (con sus condicionantes) en un determinado momento del presente:

Resulta necesario admitir, por consiguiente, una especie de inversión de perspectiva, y renunciar a considerar la autobiografía a la manera de una biografía objetiva, regida únicamente por las exigencias del género histórico. Toda autobiografía es una obra de arte, y, al mismo tiempo, una obra de edificación; no nos presenta al personaje visto desde fuera, en su comportamiento visible, sino la persona en su intimidad, no tal como fue, o tal como es, sino como cree y quiere ser y haber sido. Se trata de una especie de recomposición realzada del destino personal (1991: 16). 
Siguiendo los lineamientos generales de Gusdorf, Philippe Lejeune desplaza el centro de interés de la antropología, por la normativa jurídica, en el sentido de que afirma que la autobiografía es un modo de lectura tanto como un tipo de escritura.

En su libro El pacto autobiográfico, Lejeune, en una obsesiva preocupación estructuralista por denominar, caracterizar y sistematizar, define la autobiografía a partir de la posición del lector como un "relato retrospectivo en prosa que una persona real hace de su propia existencia, poniendo énfasis en su vida individual y, en particular, en la historia de su personalidad" (1991: 48). Con ello insiste en que los elementos de su definición (narración, prosa, historia de la personalidad, identidad del autor y del narrador, visión retrospectiva del relato) distinguen el género de las memorias, la biografía, la novela personal, el poema autobiográfico, el diario íntimo y el autorretrato o ensayo.

La distinción del género no estriba en las características estructurales ni textuales, sino solamente en la firma que aparece en la portada. En una declaración que reduce los tópicos de la escritura del género, indica que "debemos situar los problemas de la autobiografía en relación con el nombre propio" (1991: 51). Esta marca en el texto resume toda la existencia del autor, lo cual es la única señal de una realidad extratextual indudable que envía a una persona real la responsabilidad de la enunciación.

Esta estrecha argumentación necesita, como supuesto, de un concepto unívoco de identidad, entendida como la suma de características inherentes a un sujeto histórico, determinaciones que el lector tiene que reconocer. Por ello dice Lejeune que "la autobiografía no conlleva gradaciones: o lo es o no lo es" (1991: 52). Pero ¿qué pasa con las autobiografías a las que el autor no firma con su nombre propio, sino que usa un seudónimo? Para Lejeune -obviando el propio texto, lo que está después de la firma- esto no es autobiografía: "El héroe puede parecerse tanto como quiera al autor: mientras no lleve su nombre, no tiene nada que ver con él" (1991: 52). Esto implica, también, que el autor de una autobiografía no puede ser anónimo.

Dice Lejeune que un texto de aspecto autobiográfico que nadie asume como tal se parece a una obra de ficción: "Lo que define la autobiografía para quien la lee es, ante todo, un contrato de identidad que es sellado por el nombre propio. Y eso es verdad también para quien escribe el texto. Si yo escribo la historia de mi vida sin decir mi nombre, ¿cómo sabría el lector que se trata de mí? Resulta imposible que la vocación autobiográfica y la pasión de anonimato coexistan en el mismo ser" (1991: 55). Ante esta pregunta cabría hacerle otra a Lejeune, igualmente desconcertante ¿y si el autor pretende mentir?

En consecuencia, lo que constituye un texto como autobiografía es el pacto autobiográfico, que consiste en la afirmación en un texto de la identidad del autor, pacto que envía al nombre del autor sobre la portada:

La identidad se define a partir de tres términos: autor, narrador y personaje. El narrador y el
personaje son las figuras a las cuales remiten, dentro del texto, el sujeto de la enunciación y el
sujeto del enunciado; el autor, representado por su nombre, es así el referente al que remite, por
el pacto autobiográfico, el sujeto de la enunciación (1991: 56).

La autobiografía, entonces, no es un texto de ficción, es escritura referencial igual que el discurso científico o histórico, y pretende aportar una información sobre una realidad extratextual, por lo que se somete a una prueba de verificación. Por ello resulta imprescindible que el pacto autobiográfico sea establecido y mantenido a lo largo de todo el texto. 
Un texto deviene autobiográfico en la medida en que yo como lector establezco un contrato de veridicción con el sujeto que firma el texto, y con ello le creo lo que me relata, es decir, confío en la construcción del yo autobiográfico que realiza, en ese momento de la lectura, un sujeto de enunciación determinado. La valoración del género abandona el texto y se dirige a la confianza esperada en una firma. A la vez, ese efecto contractual no es igual para todas las épocas, varía históricamente; por ello "la historia de la autobiografía sería, entonces, más que nada, la de sus modos de lectura: historia comparada en la que se podría hacer dialogar a los contratos de lectura propuestos por diferentes tipos de textos (...) y los diferentes tipos de lecturas a que esos textos son sometidos (1991: 61).

\section{La autobiografía, el ámbito de la escritura}

En su ensayo "La autobiografía como desfiguración" Paul de Man empieza preguntándose por la relación entre los conceptos que han marcado la definición del género autobiográfico: historia y ficción, y termina inclinándose por valorar no la autobiografía como género, sino la textualidad denominada "autobiografía", y considerando el elemento ficticio, es decir, estudiando los elementos retóricos que construyen la ficción autobiográfica:

\footnotetext{
Asumimos que la vida produce la autobiografía como un acto produce sus consecuencias, pero ¿no podemos sugerir, con igual justicia, que tal vez el proyecto autobiográfico determina la vida, y que lo que el escritor hace está, de hecho, gobernado por los requisitos técnicos del autorretrato, y está, por lo tanto, determinado, en todos sus aspectos, por los recursos de su medio? (1991: 113).
}

De Man se cuestiona si no será que el sujeto autobiográfico es el que determina el referente, y este crea la ilusión referencial. Afirma que la autobiografía no es un género sino una figura de lectura y de entendimiento que se produce en todo texto, y el momento autobiográfico (que es lo que existe) se presenta como una alineación entre los sujetos implicados en la lectura, en la cual ambos se determinan por una sustitución reflexiva mutua. Esto implica una relación especular que "está interiorizada en todo texto en el que el autor se declara sujeto de su propio entendimiento, pero esto meramente hace explícita la reivindicación de autoridad que tiene lugar siempre que se dice que un texto es de alguien y se asume que es inteligible precisamente por esa misma razón" (1991: 114).

Ese momento especular no es primordialmente una situación o un acontecimiento que puede ser localizado en una historia, sino la manifestación de una estructura lingüística. Ese momento especular revela la estructura tropológica que subyace a todo conocimiento, incluido el de uno mismo, tal como se presenta en el caso de los textos autobiográficos. Por ello, "el interés de la autobiografía (...) no radica en que ofrezca un conocimiento veraz de uno mismo -no lo hace, sino en que demuestra de manera sorprendente la imposibilidad de totalización (es decir, de llegar a ser) de todo sistema textual conformado por sustituciones tropológicas" (1991: 114). Por estas razones, de Man cuestiona el planteamiento de Lejeune. Señala que este autor se desplaza de la autoridad especulativa a la autoridad de carácter legal, en el sentido de que afirma que la identidad de la autobiografía no es solo representacional sino contractual, basada no en tropos sino en actos de habla. Por tanto, el nombre del autor autobiográfico no es el de un sujeto capaz de autoconocimiento, sino la firma que le da autoridad legal. El lector, en vez de ser figura especular se convierte en juez que verifica la autenticidad de la firma y del comportamiento del firmante. 
De Man insiste en que antes que estudiar al sujeto en tanto individuo, es necesario considerar el texto especular como una estructura retórica, es decir, analizar los elementos tropológicos con que el sujeto de enunciación se construye como referente (más bien como ilusión de referencialidad):

\footnotetext{
En la medida en que el lenguaje es figura (o metáfora, o prosopopeya), es realmente no la cosa misma, sino su representación, la imagen de la cosa y, como tal, es silencioso, mudo como las imágenes lo son. El lenguaje, como tropo, produce siempre privación, es siempre despojador (1991: 118).
}

De aquí la imagen de la autobiografía como desfiguración, lo cual implica dos peligrosas conclusiones a las que llega de Man. Primero, si el texto es sólo tropología, se desplaza el interés por lo antropológico, y segundo, al desaparecer tal preocupación, no queda ningún lugar para la referencialidad, el espacio donde se sitúa el sujeto de enunciación, tal como lo indica Iris Zavala:

La "desconstrucción metafísica" pone de relieve, en última instancia, que el sujeto es lenguaje, y éste un juego tropológico de metáforas y metonimias, y por tanto no existen ni el sujeto ni el objeto de conocimiento (1991a: 41).

Esta perspectiva posmoderna, polo opuesto a la visión de Dilthey, deja por fuera un hecho relevante para nosotros: que la autobiografía es antes que nada una construcción discursiva de enunciados históricos, un género secundario como dice Bajtín, y con ello se introducen los problemas de la referencialidad (con sus mediaciones, por supuesto) del lenguaje y de la construcción de la forma artística, aspecto único por el que se inclina de Man.

\section{La autobiografía como espacio dialógico}

Entendemos el género literario como un sistema referencial adscrito a una comunidad histórica que valida determinado número de reglas epistemológicas, las cuales asignan validez (veridicción) y verosimilizan los cánones genéricos que consumen. Tal aprehensión se vehiculiza conforme con un proceso de conservación y renovación, que por un lado modeliza el canon adaptándolo, y por el otro prepara la plataforma de próximas transformaciones, en su diálogo con el espacio social en que se efectúa. Dichos caracteres consensuados se deben aceptar como registros (entendiendo este concepto como los "géneros existentes" en el horizonte de expectativas del lector-escritor) verosímiles, no obstante que surjan textos que confronten las reglas de veridicción.

Sin embargo, tal procedimiento de verosimilización por diferencia, aunque es más complejo - ocupa un mayor esfuerzo por parte del lector- y produce un índice elevado de resistencia, se estructura (y semantiza) a partir de los recursos de verosimilización por semejanza. Así pues, tales reglas genéricas, antes que esencialidades, hay que considerarlas sistemas de modelización discursivo-funcionales.

Como ejemplo de lo que afirmamos, podemos citar la autobiografía El río, novelas de caballería, del escritor y político guatemalteco Luis Cardoza y Aragón. Este texto es una de esas escrituras que confronta las reglas de veridicción tradicionales en la estructuralidad del género 
autobiográfico (identificación texto - historia). Esta situación implica una nueva perspectiva: dicho texto se verosimiliza por diferencia ante el corpus textual con el que dialoga en tanto forma artística, mientras que se verosimiliza por semejanza con las reglas de la epistemología contemporánea (Levinas, Bachelard, Bajtín), en el sentido de que impugna la identidad del lenguaje como portador de la verdad y alude a la realidad como una construcción textual.

Quizá la principal determinación del género autobiográfico sea una subyacente paradoja: su desplazamiento de la referencialidad a la ficción. Para aquellos autores como Dilthey, quienes veían en esos escritos impolutos reportajes de la verdad del autobiógrafo, y más aún, un instrumento preciso de conocimiento histórico, era indudable e imposible no imaginar un efecto de reflejo gnoseológico: lo que se escribe corresponde con una realidad vivida, perspectiva que hoy por supuesto no podemos aceptar. Tal correspondencia se leía con una credibilidad absoluta hacia ese "pacto autobiográfico" del que habla Lejeune, fuera de cualquier consideración de las mediaciones, las instituciones, etc.

Esta marca de referencialidad que carga la tradición en el género que examinamos se debe en mucho a su asociación con el género histórico de la biografía y a un aspecto pragmático que lo caracteriza: la correferencialidad entre autor, enunciador textual y héroe, lo que provoca una ilusión de referencialidad muy preciada desde el punto de vista de la constitución verosimilizante del género.

Se evidencia que en el horizonte de expectativas del lector, el género autobiográfico mantiene una elevada carga de referencialidad, heredera de esa tradición que estima el género como portador de la verdad del escritor. En ese mismo horizonte ronda la certidumbre de descubrir en los escritos autobiográficos la identidad del escritor. A pesar de que como demuestra Gusdorf, el héroe de la autobiografía es otro sujeto, aquel anhelado por la inestable memoria del sujeto-escritor, su yo-proyección, su "autos" deseado y corregido para un ansioso lector. Y todavía, la identidad deseada es aquella que un determinado sistema cultural le ha provisto al escritor, tal como indica Celia Fernández Prieto:

\footnotetext{
...no existe una identidad previa al hecho de narrarla, que el acto mismo de narrarla es también el de crearla, y que esa narración (como toda narración) es siempre teleológica, de una forma o de otra hay un "caso" que explicar y justificar que a menudo es la teoría que el autobiógrafo tiene de sí mismo en el presente de su escritura (1994: 124).

La identidad se alcanza precisamente cuando el lector acepta esa versión (esa figuración, esa representación) del yo y la valora como cierta, esto es, como la incierta verdad de la autobiografía (1994: 130).
}

La búsqueda de tal identidad es infructuosa, ya que en el género que estudiamos, ese sujeto (como intertexto de una multiplicidad de otros) que construye su mejor imagen, narrativiza una identidad, o una suma de ellas. Tal categoría deviene resultado de la escritura como palabra socioideológica, y no reflejo de una personalidad que se copia a sí misma. Más aún, constatar una identidad determinada es un objetivo un tanto ilusorio si se piensa en una esencialidad fija, ya que, como bien apunta Fernández Prieto, "lo que consideramos realidad y lo que consideramos ficción depende de convenciones culturales y sistemas de creencias. De ahí que la frontera entre ambas categorías sea porosa e inestable. No cabe hablar de un salto ontológico entre lo real y lo ficcional, sino siempre de formas de interrelación que se actualizan en modos y grados distintos según los códigos de género" (1994: 121). 
Por ello, lo más conveniente quizá no sea fijar un ámbito para la autobiografía (el de la identidad ontológica, el de la ficción, el del testimonio antropológico, el de la retórica...), sino seguir esas formas de interrelación, aquellas fronteras inestables en que hallemos elementos de variada naturaleza y miremos la escritura como artificio y como enunciado histórico-social, intertextualidad que se permite los desplazamientos.

Muy justos nos parecen, entonces, los reclamos de Paul de Man, en tanto que aspectos extratextuales como la antropología, el derecho, la personalidad, etc. han desplazado el análisis de la escritura, de la estructura retórica de la autobiografía, lo que no ha permitido distinguir la construcción tropológica de este tipo de textos. Su problema radica en sólo observar ésta, y no percibir el texto autobiográfico como enunciado.

El punto de vista es acertado si se considera, no como quería de Man, un traslado de perspectiva fundado en la negación de la autobiografía como género u objeto de conocimiento, sino una ruta más del desplazamiento reflexivo, el análisis de un ámbito excluido, que entraría en diálogo con la construcción de un sujeto, la visión de determinados referentes, etc., a los cuales vehiculiza la tropología objeto de atención de Paul de Man.

El texto autobiográfico permite esta pluralidad de requerimientos y posibilidades de análisis debido a la particular ambigüedad que lo caracteriza, es decir su discursividad, en tanto escritura, de textualizar las formas de lo real y lo ficticio, lo que se manifiesta en los distintos planos de su red discursiva: "el semántico, por cuanto su tema es la identidad, su fuente informativa, la memoria, y sus materiales, los recuerdos del pasado; el sintáctico, por cuanto se vierte en el cauce de la narración con sus modos de figuración temporal: tiempo de la vida o, mejor, del vivir/ tiempo de la escritura; tiempo de la narración/ tiempo de lo narrado; y el pragmático, por ese peculiar juego de distancias, identificaciones y divergencias entre las diferentes instancias de enunciación y enunciado: autor- narrador, narrador-personaje y autor-personaje" (Fernández Prieto 1994: 121-2).

Ante esta multiplicidad de formas de comprensión del género autobiográfico, es necesario asumir una posición para dejar clara nuestra perspectiva de entendimiento y asunción del género.

Entendemos la autobiografía a partir de las reflexiones de Bajtín sobre el héroe. Consideramos dos momentos en la reflexión bajtiniana acerca del héroe. La primera, en su trabajo "Autor y personaje en la actividad estética", escrito entre 1920 y 1924 e incluido en su Estética de la creación verbal; y la segunda en Problemas de la poética de Dostoievski (1929).

En el primero de estos trabajos, al analizar el problema del héroe como una totalidad de sentido, Bajtín coincide con Neumann al señalar que, en tanto género, la autobiografía aparece durante el Renacimiento (aunque se conocen formas intermedias entre la confesión y la autobiografía desde la antigüedad clásica). Analiza el autor, por tanto, la relación texto-historia.

Indica que no existe una frontera brusca y fundamental entre autobiografía y biografía. En ambos discursos, la actitud hacia uno mismo (yo-para-mí) no es el elemento básico de organización y de estructuración de la forma, como sí lo es para el género confesional.

Por biografía o autobiografía, Bajtín entiende "la forma transgrediente más elemental mediante la cual yo puedo objetivar mi vida artísticamente" (1920-24: 133). En la autobiografía se manifiesta una coincidencia entre el héroe y el autor, desde el punto de vista de un carácter particular del autor con respecto al héroe. Asimismo, una autobiografía de carácter literario debe poseer valores biográficos. Para el teórico, el valor biográfico es aquel "que entre todos los valores artísticos transgrede menos a la autoconciencia; por eso el autor, en una autobiografía, se aproxima máximamente a su héroe, ambos pueden aparentemente intercambiar 
sus lugares, y es por eso que se hace posible la coincidencia personal del héroe con el autor fuera de la totalidad artística" (1920-24: 134).

Para el crítico, un elemento importante de la autobiografía es el carácter de otredad competente, puesto que el biógrafo conoce gran parte de su vida gracias a las palabras ajenas del prójimo, valoraciones que poseen una tonalidad emocional determinada: nacimiento, origen, sucesos, etc., especialmente los de la niñez y la adolescencia:

Sin estos relatos de otros mi vida no sólo carecería de plenitud de contenido y de claridad, sino que permanecería internamente fragmentada, falta de unidad biográfica valorable (...) Se trata tan sólo de una participación apretada y orgánicamente valorativa en el mundo de los otros que hace que la auto-objetivación biográfica de la vida sea productiva y competente (Bajtín 1920-24: 137).

Por tanto, dos son los elementos constituyentes del género autobiográfico: la amplitud del mundo biográfico a la esfera del "yo" autoral, y el carácter de otredad competente, las voces de los otros que constituyen una extensión fundamental en la vida. Aspecto, este último, que nos parece más rescatable de su posición inicial, ya que, como bien señala Nora Catelli, este trabajo corresponde a un Bajtín "neokantiano y cristiano ortodoxo, quien para ilustrar el doble movimiento de la construcción del héroe en la novela y del yo en la autobiografía utiliza una metáfora tan arriesgada como la de la encarnación de Cristo" (1991: 13).

Señalamos antes que Bajtín considera la existencia no de un género autobiográfico en la antigüedad grecorromana, pero sí de formas autobiográficas. En el apartado tercero ("La biografía y la autobiografía antiguas grecorromanas") de su ensayo "Formas del tiempo y el cronotopo en la novela (Ensayos sobre poética histórica)", indica el autor que en el terreno griego clásico se distinguen dos tipos de autobiografía: a) el platónico, donde la autoconciencia biográfica está ligada a las formas clásicas de las metamorfosis mitológicas; y b) la autobiografía y la biografía retóricas. En este segundo tipo descansa el "encomion", del discurso cívico póstumo y conmemorativo que sustituyó al lamento.

Tales formas autobiográficas se caracterizaban porque "eran actos cívico-políticos verbales de glorificación o autovaloración públicas de personas reales" (1937-38: 324). En ellas la unidad del hombre y su autoconciencia eran puramente públicas y tenían un carácter normativo-pedagógico; el hombre estaba proyectado hacia el exterior. Esto diferencia tales formas del género autobiográfico.

Las autobiografías romanas presentan una autoconciencia público-histórica y estatal. "Las autobiografías y memorias romanas se componen en un cronotopo real algo diferente. La familia romana constituye su terreno. En este caso, la autobiografía es un documento de la autoconciencia familiar gentilicia" (1937-38: 330). El carácter personal y privado no tiene sentido, ya que la autobiografía alude a iniciativas estatales, como por ejemplo a las guerras.

También existen tres formas en donde se evidencia el inicio del proceso de privatización de la vida: 1) la representación satírico irónica o humorística de sí mismo y de su vida en las sátiras y diatribas (Horacio, Ovidio y Propercio); 2) las cartas de Cicerón a Atico; y 3) el tipo estoico de autobiografía, donde incluye Bajtín (1937-38: 336-8) las "consolaciones", diálogos basados en la filosofía consoladora.

Para nuestro concepto nos parece más conveniente el planteamiento del autor en el capítulo segundo de Problemas de la poética de Dostoievski (1929), en donde entiende al héroe 
como una autoconciencia dialógica no concluida:

La autoconciencia, como dominante artística de la estructuración del héroe, no puede ser equiparada a otros atributos de su imagen, porque absorbe a éstos como su propio material y los despoja de toda fuerza determinante y conclusiva del héroe (1929: 75).

Por tanto, la autobiografía es un conjunto de enunciados que presentan la constitución de la autoconciencia de un sujeto ficcional, textualización que se prefigura como sujeto heroico en una construcción enunciativa. La autoconciencia, por supuesto, no está dada esencialmente, sino que su elaboración se construye en la tensión entre lo semiótico y lo simbólico, entre las fuerzas centrípetas y las centrífugas, tensión que se vehiculiza entre mecanismos de asimilación y rechazo. Con ello observamos el nivel del texto como enunciado (habitado por un sujeto de enunciación y un sujeto del enunciado), lo que lo relaciona con su historicidad y su contexto de enunciación. Pero más importante es aún indicar que la perspectiva nos parece válida porque las escrituras autobiográficas se deben entender en relación con los demás textos que configuran esta tradición formadora de género.

\section{Conclusiones}

Los escritos autobiográficos tienen su origen en el Renacimiento Occidental, específicamente con la evolución del pensamiento simbólico al sígnico, debido al interés que se suscitó en la época por la figura humana y, más aún, por el concepto de individualidad. Consecuentemente, el nacimiento del género corresponde al establecimiento y consolidación de la burguesía en Occidente; concretamente responde a su valoración exacerbada del concepto de individualidad. La autobiografía es el resultado, entonces, de la conciencia individual que se considera digna de interés tanto para los demás como para la historia.

Por otra parte, los estudios del género autobiográfico se inician en el siglo pasado, con la figura de W. Dilthey, quien en su preocupación por la hermenéutica histórica, consideró la autobiografía como un instrumento muy valioso para el conocimiento histórico, ya que para él lo que decía el escritor correspondía directamente con el referente. Este autor inicia la etapa de la autobiografía como "bios", es decir, la escritura como reflejo de la vida del autor.

Georges Gusdorf, por su parte, analiza la autobiografía como la construcción de un sujeto ficticio por parte del autor. Lo que se escribe es lo que se quiere representar de un pasado desde el presente de la escritura. A esta perspectiva corresponde la etapa del "autos", la elaboración de un yo por la memoria autobiográfica.

El escritor norteamericano Paul de Man reacciona ante los ejes de carácter antropológico en la consideración de la autobiografía y comienza negando el género, para indicar que lo que existe son momentos especulares en donde se reflejan dos sujetos (el de enunciación y el autobiográfico) mediante una tropología particular que se ha considerado como "autobiográfica". El autor intenta recuperar este tipo de textos como formas discursivas (es la perspectiva de la autobiografía como escritura), como literatura, antes que documentos cognoscitivos.

Poco provechoso para la teoría literaria nos parece la negación de la autobiografía como género, debido, entre otras razones, al horizonte de expectativas de nuestra época, en donde se lee y se produce en abundancia este tipo de escritos; incluso, importantes empresas editoriales, como Tusquets Editores, poseen colecciones dedicadas al género; pero más allá del es- 
pacio netamente comercial, una comunidad lee y escribe autobiografías siguiendo la iniciativa de San Agustín. Independientemente de los reproches y las apologías, la autobiografía constituye una parte, siguiendo los términos de Françoise Pérus (1982: 23), de nuestra formación ideológica estético-literaria.

Bajtín permite considerar el género como dialogía, un espacio de enunciación que posibilita escuchar la voz de los otros que son los que me constituyen, a la vez género que remite a los problemas de la constitución del sujeto, el cual, para el crítico, no puede ser analizado desde una óptica monológica, debido a que "un sujeto como tal no puede ser percibido ni estudiado como cosa, puesto que siendo sujeto no puede, si sigue siéndolo, permanecer sin voz; por lo tanto su conocimiento sólo puede tener carácter dialógico" (1974: 383).

Las autobiografías despiertan interés tanto desde el punto de vista de la construcción de un sujeto (nivel antropológico), como desde el eje literario, es decir, la elaboración y la conjugación de estructuras tropológicas particulares. A fin de cuentas, el género autobiográfico se ha constituido en un espacio dialógico, ambiguo, donde conviven elementos referenciales, antropológicos, culturales, encubiertos en una estructura tropológica y pragmática que lo distinguen de otros espacios de escritura.

Es gracias a estos desplazamientos que dicho género se ha visto acechado por múltiples enfoques disciplinarios que intentan seducirlo y alistarlo en sus filas. Más allá de estos intereses siguen vigentes sus estructuras verosimilizantes en tanto género histórico, transformándose conforme se modifican los espacios socio-textuales que lo consumen, pero siempre subyugando el interés, por los atractivos de ese particular "tejido en el que la autoconciencia se enhebra delicadamente a través de experiencias interrelacionadas" (Weintraub 1991: 19), donde un sujeto de enunciación se inventa, actor que dibuja en su escenario las imágenes que más lo seducen para luego integrarse al público y observar su espejo lleno de palabras que nunca fueron suyas.

\section{Bibliografía}

Bajtín, Mijaíl. 1985 (1920-24). "Autor y personaje en la actividad estética". Estética de la creación verbal. Trad. de Tatiana Bubnova. Segunda edición. México: Siglo Veintiuno Editores,.

1986 (1937-38) "Formas del tiempo y del cronotopo en la novela. (Ensayos sobre poética histórica)". Problemas literarios y estéticos. Trad. de Alfredo Caballero. La Habana: Editorial Arte y Literatura, 1986.

1986 (1963). Problemas de la poética de Dostoievski. Trad. de Tatiana Bubnova. México: Fondo de Cultura Económica.

1985 (1974). "Hacia una metodología de las ciencias humanas". Estética de la creación verbal. Trad. de Tatiana Bubnova. Segunda edición. México: Siglo Veintiuno Editores.

Caballé, Anna. 1987. "Figuras de la autobiografía". Revista de Occidente. Madrid. N.74-75, 
julio-agosto.

De Man, Paul. 1991. "La autobiografía como desfiguración". La autobiografía y sus problemas teóricos. Barcelona: Suplementos Antropos. N. 29, diciembre.

Dilthey, Wilhelm. 1944. El mundo histórico. Trad. de Eugenio Imaz. México: Fondo de Cultura Económica.

Fernández Prieto, Celia. 1994. "La verdad de la autobiografía". Revista de Occidente. Madrid. N. 154, marzo.

Gusdorf, Georges. 1991. "Condiciones y límites de la autobiografía". La autobiografía y sus problemas teóricos. Barcelona: Suplementos Antropos. N. 29, diciembre.

Lejeune, Philippe. 1991. "El pacto autobiográfico". La autobiografía y sus problemas teóricos. Barcelona: Suplementos Antropos. N. 29, diciembre.

Neumann, Bernd. 1973. La identidad personal: autonomía y sumisión. Trad. de Hernando Carvajalino. Buenos Aires: Sur.

Olney, James. 1991. "Algunas versiones del bios: la ontología de la autobiografía." En: La autobiografía y sus problemas teóricos. Barcelona: Suplementos Antropos. N. 29, diciembre.

Pérus, Françoise. 1982. Historia y crítica literaria. La Habana: Casa de las Américas.

Schmeling, Manfred y otros. 1984. Teoría y praxis de la literatura comparada. Barcelona: Editorial Alfa.

Weintraub, Karl. 1991. "Autobiografía y conciencia histórica". En: La autobiografía y sus problemas teóricos. Barcelona: Suplementos Antropos. N. 29, diciembre.

Zavala, Iris. 1991a. "La autobiografía como suplemento: Unamuno." En: Revista Anthropos. No. 125, octubre. 